DOI: 10.17234/SRAZ.65.41

UDK: 81'373.7

Original scientific paper

Recibido el 28 de abril de 2020

Aceptado para la publicación el 25 de noviembre de 2020

\title{
Buscando equivalencias interlingüísticas entre unidades pluriverbales con componente cultural
}

Maciej Pawet Jaskot

Universidad Pedagógica de Cracovia

maciej.jaskot@up.krakow.pl

El presente artículo se centra en la cuestión de la correspondencia interlingüística de unidades fraseológicas (UFs) que presentan un fuerte anclaje cultural. Estas UFs se refieren a los códigos culturales, que reflejan la experiencia humana en la lengua, donde se almacenan y acumulan las imágenes conceptuales de las UFs. Se propone denominar las UFs que tienen una base cultural sólida culturemas fraseológicos, puesto que tales UFs hacen de codificadores del contenido cultural, a saber, de la imagen lingüística mundo de una comunidad cultural.

Palabras clave: fraseología contrastiva, linguoculturología, culturemas fraseológicos, códigos culturales

\section{Introducción}

El enfoque cognitivo no solo brinda la posibilidad, sino también hace hincapié en la necesidad de incorporar en las investigaciones lingüísticas el análisis de elementos extralingüísticos. La cultura, con sus numerosas manifestaciones, deja una profunda huella en la lengua, que incide en la semántica tanto de los lexemas como de las unidades pluriverbales, siendo un factor insoslayable a la hora de determinar el significado de dichas unidades. Esta impronta cultural, a su vez, apela a los códigos culturales, que determinan la idiosincrasia de cada comunidad lingüística. La identificación de dichos códigos es imprescindible para poder establecer equivalencias con otras lenguas. Los códigos culturales, reflejados en las unidades léxicas y fraseológicas permiten hablar de culturemas y culturemas fraseológicos.

\section{Linguoculturología o lingüística cultural}

El campo de la ciencia que se ocupa de las relaciones entre la lengua y la cultura es la lingüística cultural, también llamada linguoculturología (v. Vorob'ev 1997 y Vasilûk 2010). El primer término fue definido por Anusiewicz (1994) de la siguiente manera: 
La lingüística cultural es una ciencia que estudia la relación entre lengua y cultura. La lengua se percibe como un prerrequisito de la cultura, un componente, depósito, "correa de transmisión", interpretación y elemento interpretador que contiene el contenido cultural. La tarea principal de la lingüística cultural es estudiar la relación de cuatro factores: lengua - cultura - ser humano (sociedad) - realidad.

El enfoque linguoculturológico en el ámbito de los estudios fraseológicos se manifiesta mediante el estudio de varias formas de interacción entre la cultura y la lengua. Tales interacciones llevan a la formación de UFs, que son elementos que incorporan y generan la transmisión a largo plazo de la información cultural. Una comprensión clara del proceso de esta interacción, así como la comprensión de cómo la información cultural se traduce en significado fraseológico, actualmente es uno de los principales problemas del enfoque linguoculturológico en la fraseología.

Zykova (2014) señala que a partir del concepto de "memoria cultural" es posible demostrar que el significado fraseológico es una formación semánticoconceptual compleja, que puede reflejar varias modalidades (aplicadas a lo largo de la historia) de entender el mundo y, por lo tanto, preservar diferentes tipos de información cultural (p. ej. en referencia a los arquetipos, mitos, la religión, filosofía, ciencia, etc.).

\section{Los códigos culturales en la lengua}

Los códigos culturales son como una "red" que la cultura "arroja" sobre el mundo categorizándolo y valorándolo (Krasnykh 2002: 232). Valiéndonos de esta metáfora, podemos entender la cultura como espacio de sentidos culturales que surgen en el proceso de experimentar el mundo. En otras palabras, la cultura es un espacio de códigos, que a su vez son sistemas secundarios que utilizan diversas materias y medios formales para codificar el mismo contenido (Teliia 1996: 217). Por consiguiente, la imagen del mundo de una comunidad se ve codificada en los significados culturales ${ }^{1}$. Investigar los etnocódigos y los códigos culturales es una tarea imprescindible en los estudios linguoculturológicos, que -entre otros aspectos- se centran en la correlación de las UFs con las imágenes mentales, la semántica de sus componentes y su realización en una lengua. ${ }^{2}$

1 “Codes can be used both consciously and unconsciously and they are invariably difficult to comprehend. Like an enigmatic crossword, it is necessary to divine the rules that will expose the underlying themes to enable the puzzle to be fitted together. However, unless the codes are cracked we are left floundering in a world of assumption, guesswork and false premise. This means that our ability to influence change, through evaluation and other similar processes, is significantly curtailed. We are in danger of acting on miscomprehension which means that our efforts to bring about change are likely to be misdirected". (Hyatt, Simons 1999: 28)

2 "[Piirainen] defiende que los símbolos culturales, aunque se integren en las metáforas fijadas por la lengua, mantienen un valor "autónomo". Así, las expresiones que contienen la palabra pan (esp. más bueno que el pan; ganarse el pan; quitarle el pan de la boca a alguien) tienen un significado global en parte predecible a partir del valor simbólico 
De ahí que, como afirma Givón (1995), el lexicón de cualquier lengua sea una fuente de informaciones culturales:

El lexicón representa el total de la diversidad interlingüística culturalmente específica. La diversidad representada en el lexicón es la de la visión del mundo, es decir, la visión de un grupo social sobre un universo conceptual relativamente estable. Givón (1995: 18)

El código cultural, reflejado ya a nivel de lexemas, es un conjunto de signos y un sistema de reglas definidas mediante el cual la información puede representarse como un conjunto de símbolos utilizados para la transmisión, el procesamiento y el almacenamiento del contenido cultural. La necesidad de un código cultural surge cuando se da la transición del mundo de los signos al mundo del significado. El código cultural permite decodificar el significado convertido y proporciona reglas para formar una serie de mensajes específicos. Todos los códigos son comparables sobre la base de un código común, más simple y más completo. El código cultural permite llegar al nivel semántico de la cultura; su desconocimiento hace que la información cultural del texto sea incomprensible.

Se han llevado a cabo varias clasificaciones de los códigos culturales (entre otros Krasnykh 2002; Savchenko 2013) reflejados en la lengua. La mayoría de ellas se basa en la clasificación de dominios relacionados con la realidad extralingüística. Proponemos una posible clasificación de los códigos culturales reflejados por UFs españolas y croatas ${ }^{3}$ :

- $\quad$ somáticos, p.ej.

- $\quad$ biti bez glave i repa, imati oštar jezik, nemati dlake na jeziku, za dlaku, za lizati prste,

- perder la cabeza, no tener pelos en la lengua, por los pelos

- $\quad$ espaciales, p.ej. a dos pasos, na dohvat ruke

- gastronómicos, p.ej.

- ide, prodaje se kao halva, prošla baba s kolačima, dobar kao kruh

- llamar al pan pan y al vino vino

- temporales, p.ej. biti u godinama

- cromáticos, p.ej.

- crni humor, gledati kroz ružičaste naočale,

- ver el mundo de color de rosa, a buenas horas mangas verdes

- zoomórficos, p.ej.

- lukav kao lisica, tordoglav kao magarac, biti na konju, gladan kao pas/vuk,

- hambre canina, ponerse como una cabra

- arquitectónicos, p.ej. uno de los pilares, ser la base de algo

- cuantitativos, p.ej.

- za pet je što, dati pet za devet,

del referente PAN en la cultura europea (en este caso PAN = BIEN/SUBSISTENCIA), y que no es exclusivo del significado global de tal o tal frasema particular, sino que tiene estabilidad en varios significados figurados y es incluso susceptible de generar otros nuevos". (Pamies Bertrán 2008: 41)

3 Tanto las categorías como los ejemplos propuestos son del autor. 

- en un dos por tres, como tres y dos son cinco
- religiosos y antropomórficos, p.ej.
- dječja igra, božja kazna, iznijeti istinu na sunce,
- en un santiamén, donde Cristo perdió el gorro

Las UFs siendo expresiones cuya forma interna da una imagen completa de la imagen lingüística del mundo de una comunidad lingüística, aparecen como acervos de conocimiento cultural y reguladores de ciertos comportamientos de la interacción social.

\section{La traducción de unidades fraseológicas}

El problema de la traducción de las UFs no es nuevo y aparece ya en las primeras teorías sobre la traducción entendida como una disciplina científica aparte. Algunas investigaciones ven en las UFs un enigma de la traducción, un problema sin solucionar, es decir, unidades intraducibles, mientras que otros consideran la intraducibilidad como un enfoque al problema completamente equivocado. En cuanto a la traducibilidad de lo intraducible, Zuluaga (2001) es fiel a las posiciones de Jakobson: toda experiencia cognitiva que se expresa en una lengua puede ser expresada en todos y cada uno de los idiomas existentes. Este proceso puede tener lugar mediante préstamos léxicos, calcos, neologismos, paráfrasis, circunloquios, cambios de significado, etc. Según Zuluaga (2001: 70), el uso de las UFs, a pesar de sus complejas forma y semántica, garantiza el éxito comunicativo, reduciendo al mínimo el esfuerzo necesario al expresarse. Zuluaga cree que las UFs no se pueden marcar como traducibles o intraducibles, dado que en cada caso el acto de traducción es específico. En referencia a las palabras que representan un gran reto para todos los traductores, el académico español dice: "Las UFs son signos ('supersignos') especiales con sorprendentes posibilidades funcionales propias". (2001: 71)

Spahić (2013: 159) subraya que "la referencia a aspectos y realidades idiosincrásicos, que a menudo contienen las expresiones fraseológicas, dificultan la traslación a otra lengua. Se trata de toda una serie de información proporcionada por el fraseologismo en la lengua de origen". De hecho, las UFs son unidades que tienen un fuerte anclaje cultural, ya que son "patrones sancionados por una cultura determinada" ("patterns sanctioned by a given culture"), por lo que su traducción significa, de hecho, la traducción de culturemas (Koseska-Toszewa, Satoła-Staśkowiak, Sosnowski 2013 en: Jaskot, Ganoshenko 2015). A su vez, según Luque Durán y F. J. Manjón Pozas (1988: 45) los signos fraseológicos "son más coyunturales y tienen un estatus mixto cultural-lingüístico" .

En definitiva, la UF entendida como signo es un elemento de la memoria cultural de una sociedad que habla un idioma determinado. Toda información cultural se almacena y acumula en los cimientos profundos de las imágenes conceptuales de las UFs, es decir, en los modelos conceptuales macrometafóricos (Zykova 2014: 11). La semántica de las UFs, siendo determinada por la base conceptual de la imagen del signo fraseológico, es el resultado de una 
transposición intersemiótica, entendida como la "traducción" en una forma lingüística del contenido de la esfera conceptual de la cultura, que se halla detrás de los signos no verbales de la comunidad cultural en cuestión.

\section{Culturemas fraseológicos}

Comparando la fraseología de diferentes idiomas, nos enfrentamos con unidades que tienen una base cultural sólida, porque están estrechamente relacionadas con la historia, la cultura, la experiencia de una comunidad lingüística determinada y su imagen lingüística del mundo. La esfera fraseológica de las lenguas naturales refleja las imágenes lingüísticas de la realidad que rodea a los hablantes, es decir, refleja

una interpretación verbalizada de la realidad contenida en la lengua, que puede expresarse en forma de un conjunto de juicios sobre el mundo. Estos pueden ser juicios "fijos", a saber, basados en la misma materia de la lengua, es decir, gramática, vocabulario, textos cliché (p.ej. proverbios), pero también puede tratarse de juicios presupuestos, vale decir, implícitos en las formas de la lengua, establecidos a nivel del conocimiento social o de creencias, mitos y rituales (Bartmiński 2006: 12). ${ }^{4}$

Por consiguiente, consideramos oportuno hablar de los culturemas fraseológicos. La clave para entender este concepto es el carácter lacónico de una entidad dada en la esfera connotativa, ya que -como se ha venido subrayandouna comprensión completa de la cultura fraseológica es posible solo en referencia a la realidad extralingüística y teniendo en cuenta la pragmática de la UF en cuestión. Por culturemas fraseológicos, por tanto, nos referimos a tales UFs que, a pesar de que pueden ser portadoras de la explicación de fenómenos universales, se refieren a la cultura local, de la que derivan un material semiótico específico. De ahí que los culturemas fraseológicos estén vinculados al código cultural, que Lotman define como "conjunto de información que es necesaria para la existencia de una cultura concreta, que se puede encontrar en varios textos de una cultura determinada" (Lotman 2002: 18-19). ${ }^{5}$

Los culturemas fraseológicos son uno de los posibles medios para codificar el contenido cultural, puesto que revelan una imagen específica del mundo de una comunidad cultural y están vinculados a los códigos culturales.

A modo de ejemplo de lo susodicho, sírvannos las siguientes UFs croatas: (1) dužan kao Grčka ('que tiene muchas deudas'), (2) Martin u Zagreb, Martin iz Zagreba ('hacer algo en vano'), (3) biti kuhan i pečen ('ser uña y carne'), (4) španska sela ('algo totalmente incomprensible/ignoto') ${ }^{6},(5)$ nije turska sila ('no hace falta tener prisa'), (6) pušiti kao Turčin ('fumar como un carretero'). Todas estas UFs están

\footnotetext{
4 Traducción propia del polaco

5 Traducción propia del ruso

6 Le agradezco a la prof. ${ }^{a}$ Edina Spahić su comentario sobre le etimología de esta UFs croata; de hecho, se trata de un calco fraseológico del alemán.
} 
formadas con elementos léxicos de fuerte anclaje cultural y están relacionadas a la idiosincrasia croata: se refieren a la historia, a veces reinterpretada por el prisma nacional $(1,5,6)$, a la gastronomía (3) y topografía (2) locales.

\section{Conclusiones}

Las UFs son unidades que reflejan la experiencia extralingüística de una comunidad de hablantes. Entre estas unidades podemos individuar las que de una manera particular se refieren a los códigos culturales vigentes en una comunidad de hablantes determinada. Tales UFs (que proponemos llamar culturemas fraseológicos) se basan en los modelos conceptuales macrometafóricos y se distinguen, entre otros, por generar notables dificultades a la hora de traducirlas (transponerlas semióticamente) a otras lenguas.

\section{Bibliografía}

Anusiewicz, J. (1994). Lingwistyka kulturowa. Zarys problematyki. Wrocław: Wydawnictwo Uniwersytetu Wrocławskiego.

Bartmiński, J. (2006). Jezzykowe podstawy obrazu świata. Lublin: Wydawnictwo UMCS.

Givón, T. (1995). Functionalism and grammar. Benjamins, Amsterdam \& Philadelphia.

Hyatt, J., Simons, H. (1999). Cultural Codes - Who Holds the Key? The Concept and Conduct of Evaluation in Central and Eastern Europe, en: Evaluation, 5, pp. 23-41.

Jaskot, M., Ganoshenko, Y. (2015). Culturemes and non-equivalent lexis in dictionaries, en: Cognitive Studies, Volume XV, 115-124. DOI: 10.11649/cs.2015.009

Koseska-Toszewa, V., Satoła-Staśkowiak, J., \& Sosnowski, W. (2013). From the problems of dictionaries and multi-lingual corpora, en: Cognitive Studies, Volume XIII, 113-122. DOI: 10.11649/cs.2013.007

Krasnykh, V. V. (2002). Etnopsikholingvistika i kul'turologiâ. Moskva: Gnozis.

Savchenko, L. V. (2013). Fenomen etnokodiv dukhovnoï kul'tury u frazeolohï ukraïns 'koï movy: Etymolohichnyï ta etnolinhvistychnyı̆ aspekty. Simferopol': Dolia.

Lotman, Y. M. (2002). Istoriia i tipologiia russkoŭ kul'tury. Sankt-Peterburg: Iskusstvo.

Luque Durán, J. D. D., Manjón Pozas, F. J. (1998). Fraseología, metáfora y lenguaje taurino, en: Luque Durán, J. D. D., Pamies Bertrán, A. (eds.) Léxico y fraseología. Granada: Método Ediciones, 43-70.

Pamies Bertrán, A. (2008). Productividad fraseológica y competencia metafórica (inter)cultural, en: Paremia, 17, pp. 41-57.

Spahić, E. (2013). Fraseología y traducción literaria: el caso del bosnio y del español. Tesis doctoral presentada en la Universidad Complutense de Madrid. http:// eprints.ucm.es/21657/1/T34042.pdf (19/03/2020)

Teliia, V. N. (1996). Russkaia frazeologiia. Moskva: Iazyki russkoĭ kul'tury. 
Vasilûk, I. P. (2010). Prikladnaâ lingvokul'turologiâ: Metodologičeskie principy otbora učebno- go materiala i organizacii processa obučeniâ russkomu âzyku kak inostrannomu. Moskva: Rossijskij universitet družby narodov.

Vorob'ev V. V. (1997). Lingvokul'turologiâ: (Teoriâ i metody). Moskva: Rossijskij universitet družby narodov.

Zuluaga, A. (2001). Análisis y traducción de unidades fraseológicas desautomatizadas, en: Philologie im Netz (PhiN), 16/2011, 67-83. http://web.fu-berlin.de/phin/ phin16/p16t5.htm (7/04/2020)

Zykova, I.A. (2014). Роль кониептосферы культуры в формировании фразеологизмов как культурно-языковых знаков. <https://iling-ran.ru/avtoreferats/doct_zykova_full.pdf> (11/04/2020)

\section{“Looking for interlinguistic equivalences between pluriverbal units with a cultural component"}

This article focuses on the question of the interlingual correspondence of phraseological units that have a strong cultural anchorage. These units refer to cultural codes, which are an expression of the categorization and appreciation of human experience reflected in culture. This experience is reflected in language, a system in which all cultural information is stored and accumulated in the deep foundations of conceptual images, that is, in macro-metaphorical conceptual models applied to phraseological units. It is proposed to name the phraseological units that have a solid cultural base (due to their relationship with history, culture, the experience of a given linguistic community and their linguistic image of the world) as phraseological culturemes, since they are one of the possible means to encode cultural content, being a specific image of the world of a cultural community.

Key words: contrastive phraseology, linguoculturology, phraseological culturemes, cultural codes 
